\title{
The cardiovascular effects of beta adrenergic agonist drugs administered by nebulisation
}

\author{
A. Flatt, J. Crane, G. Purdie, T. Kwong, R. Beasley and C. Burgess \\ Departments of Medicine and Community Health, Wellington School of Medicine, Wellington, New \\ Zealand.
}

\begin{abstract}
Summary: The cardiovascular effects of equal doses $(5 \mathrm{mg})$ of nebulised fenoterol, salbutamol and terbutaline were compared in 12 healthy individuals in a double-blind, placebo-controlled study. Measurements of heart rate, blood pressure, systolic time intervals, QTc interval and T-wave amplitude were made at baseline and at 15, 30, 45, 60 and 90 minutes after nebulisation. Fenoterol caused significantly greater chronotropic electrocardiographic and inotropic effects than either salbutamol or terbutaline. The peak effects after terbutaline occurred later than those after fenoterol or salbutamol.
\end{abstract}

\section{Introduction}

The inappropriate use of nebulised beta-2-adrenergic agonist drugs has been proposed as a possible factor contributing to asthma mortality in New Zealand. ${ }^{1}$ This hypothesis was supported by the finding of a subsequent study which investigated the management of patients dying from asthma in New Zealand. ${ }^{2,3}$ In those patients who had a home nebuliser and its use during the final attack was known, over one-third had used it inappropriately. ${ }^{2}$ Indeed, over one-quarter of all the patients who died from asthma during the two year period of this study had a home nebuliser available for self-administration of beta-adrenergic agonist drugs. This is in marked contrast with the situation in England, where similar asthma mortality studies have demonstrated that death from asthma outside hospital is not associated with home nebuliser use. ${ }^{4,5}$

Analysis of the specific beta-2 adrenergic agonist self-administered by the patients who died, demonstrated that there was a significantly greater proportion of fenoterol than salbutamol used when compared with national sales of these drugs, suggesting that these agents may differ in their extra-pulmonary effects or toxicity. We have previously shown that fenoterol (administered by metered dose inhaler) has significantly greater electrocardiographic, inotropic and chronotropic effects than equal doses of either salbutamol or isoprenaline. ${ }^{6}$ In this present study we have assessed the cardiovascular effects of equal doses of fenoterol, salbutamol and terbutaline as these are

Correspondence: C. Burgess M.D., M.R.C.P., Department of Medicine, PO Box 7343 Wellington South Wellington, New Zealand

Accepted: 20 September 1989 the beta-adrenergic agents most commonly administered by nebulisation in New Zealand.

\section{Subjects and methods}

Twelve healthy subjects (eight male), mean age 30 years (range 21-41 years) were studied on four occasions, at least 2 days apart, after a 4-hour fast. None of the subjects smoked and all had abstained from alcohol and caffeine-containing substances for 12 hours prior to each study. After resting supine for 10 minutes, control recordings of the systolic time intervals, high speed electrocardiogram (ECG) and blood pressure were made. The subjects then inhaled $5 \mathrm{mg}(1 \mathrm{ml})$ of either salbutamol, fenoterol, terbutaline or an equal volume of saline via a Pari inhalierboy nebuliser. The treatments were administered according to a cross-over, randomized, double-blind, Latin square design. Further recordings were made 15, 30, 45, 60 and 90 minutes following completion of nebulisation.

The systolic time intervals were measured from simultaneous high speed $(100 \mathrm{~mm} / \mathrm{s})$ photographic recordings of the ECG, phonocardiogram and carotid pulse trace. From these recordings, total electromechanical systole $\left(\mathrm{QS}_{2}\right)$, left ventricular ejection time (LVET) and pre-ejection period $\left(\mathrm{PEP}=\mathrm{QS}_{2}\right.$ - LVET $)$ were made as previously described. ${ }^{7} \mathrm{QS}_{2}$ was corrected for heart rate using an equation developed in our laboratory $\left(\mathrm{QS}_{2} \mathrm{I}=\mathrm{QS}_{2}\right.$ $+1.2 \times \mathrm{HR} ; \mathrm{QS}_{2} \mathrm{I}$ is the $\mathrm{QS}$ index corrected for heart rate). ${ }^{8}$ From the ECG the QT interval and $T$-wave amplitude were measured. The end of the QT interval was measured by extrapolating the slope of the T-wave to the baseline (P-P interval). This interval (QTc) was corrected for the heart rate 
using the Bazett formula. ${ }^{9}$ The percentage change in $\mathrm{T}$-wave amplitude from the control measurements $(\Delta T \%)$ was noted on each day. Blood pressure was measured automatically using a Vita Stat recorder.

All subjects gave written informed consent and the study was approved by the Wellington Hospital Research Ethical Committee.

\section{Statistical analysis}

A three-way analysis of variance with subject, treatment and time effects was performed on the change from control data. The significance level was adjusted for multiple comparisons by using
Bonferroni's inequality $(P<0.05 \div$ number of comparisons).$^{10}$ Hence, when a significant treatment-time interaction was present, a probability value of $P<0.0017$ was considered significant when comparisions between treatments were made at each time.

\section{Results}

There were no significant differences in the control measurements between the treatment days (Table I).

When compared to placebo (see Figure 1 and Table II), all the active agents increased heart rate, decreased electromechanical systole $\left(\mathrm{QS}_{2} \mathrm{I}\right)$, pre-

Table I Mean (s.e.m.) control values in the twelve subjects prior to treatment.

\begin{tabular}{lccrr}
\hline & Placebo & Fenoterol & Salbutamol & Terbutaline \\
\hline Heart rate (beats/min) & $63.9(2.2)$ & $62.4(1.9)$ & $61.0(2.2)$ & $61.7(2.4)$ \\
QS I (ms) & $489.5(7.5)$ & $487.6(8.1)$ & $487.8(8.2)$ & $496.2(8.2)$ \\
PEP (ms) & $111.4(5.3)$ & $109.3(4.2)$ & $110.7(4.9)$ & $116.1(5.4)$ \\
QTc (ms) & $382.2(9.0)$ & $377.1(11.6)$ & $374.0(10.0)$ & $376.9(9.4)$ \\
$\begin{array}{l}\text { Systolic blood pressure } \\
\text { (mmHg) }\end{array}$ & $115.7(2.1)$ & $113.3(2.7)$ & $113.5(2.6)$ & $115.0(2.7)$ \\
$\begin{array}{l}\text { Diastolic blood pressure } \\
\text { (mmHg) }\end{array}$ & $77.5(2.8)$ & $74.6(1.7)$ & $73.5(1.8)$ & $75.0(1.6)$ \\
\hline
\end{tabular}

$\mathrm{QS}_{2} \mathrm{I}$ - Total electromechanical systole corrected for heart rate.

PEP - Pre-ejection period.
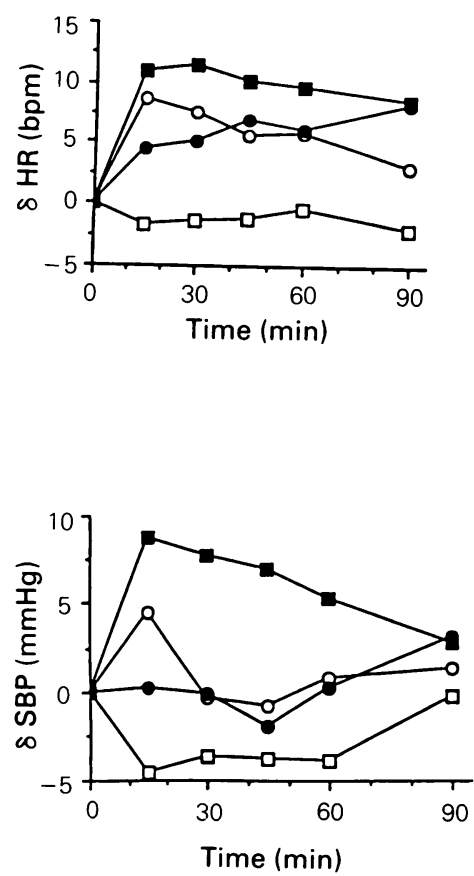
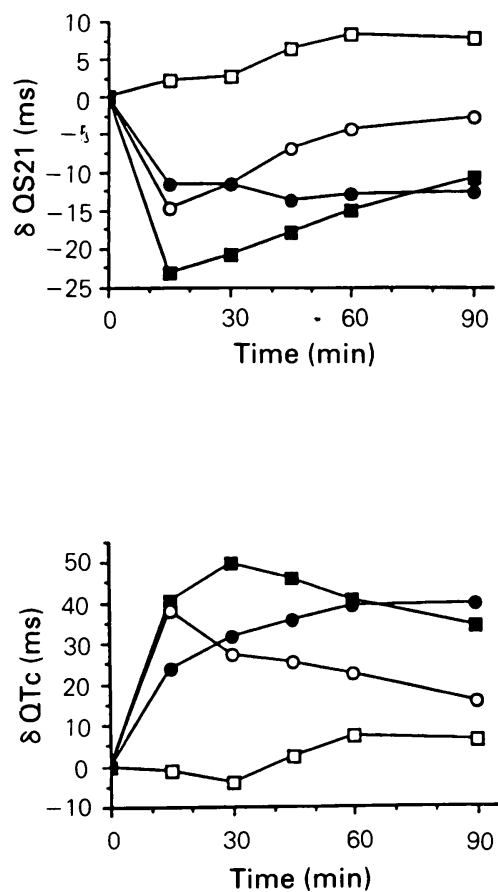

Figure 1 Effect of the treatments on heart rate (HR), total electromechanical systole $\left(\mathrm{QS}_{2} \mathrm{I}\right), \mathrm{QTc}$ interval and systolic blood pressure (SBP). $\square$, Placebo; $\square$, fenoterol; $O$, salbutamol; $\bigcirc$, terbutaline. 
Table II Effect of placebo, fenoterol, salbutamol and terbutaline on pre-ejection period (PEP), $T$ wave height and diastolic blood pressure (mean \pm s.e.m.).

\begin{tabular}{|c|c|c|c|c|c|c|c|c|c|c|c|c|}
\hline \multirow{2}{*}{$\begin{array}{l}\text { Time } \\
\text { (mins) }\end{array}$} & \multirow[b]{2}{*}{$P$} & \multicolumn{3}{|c|}{$\triangle P E P(m s)$} & \multicolumn{4}{|c|}{$\Delta T \%$} & \multicolumn{4}{|c|}{$\triangle D B P(m m H g)$} \\
\hline & & $F$ & $S$ & $T$ & $P$ & $F$ & $S$ & $T$ & $P$ & $F$ & $S$ & $T$ \\
\hline 15 & 3.5 & $-30.8 \dagger$ & $-25.0 \dagger$ & $-18.1 \dagger$ & -5.9 & $-32.8 \dagger$ & $-28.4 \dagger$ & $-20.2 \dagger$ & -2.2 & -4.1 & -6.7 & -4.5 \\
\hline & \pm 2.5 & \pm 4.8 & \pm 3.8 & \pm 4.5 & \pm 2.9 & \pm 4.1 & \pm 3.0 & \pm 3.8 & \pm 1.1 & \pm 2.0 & \pm 1.9 & \pm 1.2 \\
\hline 30 & $\begin{array}{r}2.3 \\
\pm 2.1\end{array}$ & $\begin{array}{c}-25.6 \dagger \\
\pm 3.9\end{array}$ & $\begin{array}{r}-21.7 \dagger \\
+3.1\end{array}$ & $\begin{array}{r}-19.8 \dagger \\
+3.6\end{array}$ & $\begin{array}{c}-5.2 \dagger \\
\pm 3.7\end{array}$ & $\begin{array}{c}-32.7 \dagger \\
\pm 5.4\end{array}$ & $\begin{array}{c}-28.2 \dagger \\
\pm 3.3\end{array}$ & $\begin{array}{c}-26.3 \dagger \\
\pm 4.6\end{array}$ & $\begin{array}{r}-1.6 \\
\pm 1.2\end{array}$ & $\begin{array}{r}-3.3 \\
+18\end{array}$ & $\begin{array}{r}-5.1 \\
+2.0\end{array}$ & $\begin{array}{r}-7.6 \\
\pm 17\end{array}$ \\
\hline 45 & 1.8 & $-24.6 \dagger$ & $-16.6 \dagger$ & $-21.2 \dagger$ & -6.3 & $-33.5 \dagger$ & $-25.9 \dagger$ & $-29.7 \dagger$ & -3.1 & -2.6 & -4.5 & -6.6 \\
\hline & \pm 2.8 & \pm 3.9 & \pm 2.2 & \pm 4.3 & \pm 4.3 & \pm 3.6 & \pm 2.9 & \pm 5.1 & \pm 1.1 & \pm 2.7 & \pm 1.4 & \pm 2.1 \\
\hline 60 & 4.5 & $-21.6 \dagger$ & $-13.0 \dagger$ & $-20.2 \dagger$ & -5.1 & $-30.7 \dagger$ & $-24.5 \dagger$ & $\begin{array}{r}-29.9 \dagger \\
+51\end{array}$ & -2.4 & $\begin{array}{l}-4.0 \\
+\quad 1 .\end{array}$ & -1.0 & -8.2 \\
\hline & \pm 2.9 & \pm 4.2 & \pm 2.9 & \pm 3.5 & \pm 4.1 & \pm 3.5 & \pm 3.2 & \pm 5.1 & \pm 1.7 & \pm 1.3 & \pm 2.3 & \pm 1.4 \\
\hline 90 & $\begin{array}{r}2.8 \\
+25\end{array}$ & $\begin{array}{c}-18.3 \dagger \\
+2.8\end{array}$ & $\begin{array}{l}-9.7 \dagger \\
+3.6\end{array}$ & $\begin{array}{c}-18.3 \dagger \\
+4.3\end{array}$ & $\begin{array}{l}-2.3 \\
\pm 3.4\end{array}$ & $\begin{array}{r}-29.8 \dagger \\
+3.8\end{array}$ & $\begin{array}{c}-22.1 \dagger \\
\pm 3.2\end{array}$ & $\begin{array}{c}-35.5 \dagger \\
\pm 5.3\end{array}$ & $\begin{array}{l}-2.6 \\
\pm 1.9\end{array}$ & $\begin{array}{l}-3.6 \\
\pm 1.6\end{array}$ & $\begin{array}{r}-2.0 \\
+1.6\end{array}$ & $\begin{array}{r}-1.3 \\
\pm 1.9\end{array}$ \\
\hline
\end{tabular}

$\mathrm{P}=$ placebo, $\mathrm{F}=$ fenoterol, $\mathrm{S}=$ salbutamol, $\mathrm{T}=$ terbutaline. $\dagger P=<0.0001$

ejection period and $\mathrm{T}$ wave amplitude at all times $(P<0.0001)$. Fenoterol and terbutaline increased the QTc interval at all times $(P<0.0001)$, whereas salbutamol increased this interval from 15 to 60 minutes $(P<0.005$ to $P<0.0001)$. Fenoterol increased systolic blood pressure from 15 to 60 minutes $(P<0.0001)$, whereas salbutamol increased this parameter at 15 minutes only $(P<0.0001)$. None of the drugs differed in their effect on diastolic blood pressure from placebo.

\section{Comparision of active agents}

(i) Systolic time intervals Fenoterol caused significantly greater decreases in $\mathrm{QS}_{2} \mathrm{I}$ than either salbutamol (15-90 minutes) or terbutaline (15 and 30 minutes); it also significantly decreased preejection period at 45-90 minutes when compared to salbutamol or terbutaline (15 minutes). Terbutaline significantly decreased $\mathrm{QS}_{2} \mathrm{I}$ and preejection period when compared to salbutamol (60 and 90 minutes). Salbutamol decreased pre-ejection period at 15 minutes when compared to terbutaline.

(ii) ECG Fenoterol significantly increased heart rate when compared to salbutamol $(30,45$ and 90 minutes) and terbutaline ( 15 and 30 minutes) and increased the QTc interval when compared to salbutamol (30-90 minutes) or terbutaline (30 minutes). Terbutaline increased the QTc interval and decreased $T$ wave amplitude at 90 minutes when compared to salbutamol.

(iii) Blood pressure Fenoterol caused a significantly greater rise in systolic pressure than either salbutamol (30 and 45 minutes) or terbutaline (15 to 45 minutes). Terbutaline caused a significantly greater decrease in diastolic blood pressure than salbutamol at 60 minutes.

\section{Discussion}

In this study we have shown that the administration of equal doses of nebulised beta- 2 adrenergic agonists results in different pharmacodynamic effects. In particular, nebulised fenoterol produced significantly greater inotropic, chronotropic and electrophysiological effects than equivalent doses of either salbutamol or terbutaline. The predominant difference between salbutamol and terbutaline related to a more gradual onset and a longer duration of action of the latter agent resulting in greater effects 90 minutes after nebulisation.

The marked increase in systolic blood pressure, heart rate and reduction in $\mathrm{QS}_{2} \mathrm{I}$ following administration of fenoterol indicates direct stimulation of cardiac beta- 1 and beta-2 receptors. ${ }^{11,12}$ Fenoterol also caused a significant increase in the QT interval and decrease in T-wave height. These electrocardiographic changes are of interest, for they may be associated with increased ventricular excitability. The increased risk of ventricular arrhythmias associated with QTc interval prolongation may be more common in the situation of an increase in heart rate, ${ }^{13}$ as we observed with fenoterol. When anti-arrhythmic agents, such as amiodarone, cause prolongation of the QTc interval, this is invariably associated with bradycardia. ${ }^{14}$ The changes in T-wave height may be consequent to the prolongation of the QT interval, or may be associated with hypokalaemia which has been demonstrated with beta-2 agonists. ${ }^{15,16}$

In contrast to fenoterol, the cardiovascular effects of salbutamol and terbutaline are less marked. This confirms our previous observation, that repeated inhalation of fenoterol by metered dose inhaler results in greater inotropic, chronotropic and electrophysiological effects than equal doses of salbutamol. ${ }^{6}$ These differences are primarily due to greater beta-1 adrenoreceptor stimula- 
tion following fenoterol, and are consistent with previous in vitro ${ }^{17}$ and in vivo studies. ${ }^{16}$

Although the cardiovascular effects of salbutamol and terbutaline are similar in magnitude, there were significant differences in their duration of action. The effects due to terbutaline were of slower onset and of greater duration than those following salbutamol. As a result, at the end of the 90 minute time course the cardiovascular effects of terbutaline were greater than those after salbutamol. We have observed similar differences in the time courses of the hypokalaemic effects of these agents when administered to some of these subjects. ${ }^{15}$ This difference is likely to be due to differences in bioavailability which in turn is likely to be due to differences in the preparation of these agents.

These results are of importance as they point to major differences in the clinical extra-pulmonary effects of these agents. Fenoterol is more likely to cause increased myocardial oxygen consumption, and perhaps in the setting of hypoxia may be more likely to predispose an asthmatic patient to ven-

\section{References}

1. Grant, I.W.B. Asthma in New Zealand. Br Med J 1983, 286: $374-377$.

2. Sears, M.R., Rea, H.H., Fenwick, J. et al. 75 deaths in asthmatics prescribed home nebulisers. $\mathrm{Br}$ Med J 1987, 294: 477-480.

3. Sears, M.R., Rea, H.H., Beaglehole, R. et al. Asthma mortality in New Zealand: a two year national study. NZ Med J 1985, 98: 271-275.

4. British Thoracic Association. Death from asthma in two regions of England. $\mathrm{Br} \mathrm{Med} J$ 1982, 285: 1251-1255.

5. Ormerod, L.P., Stableforth, D.E. Asthma mortality in Birmingham 1975-7: Fifty-three deaths. Br Med J 1980, 280: $687-690$.

6. Crane, J., Burgess, C. \& Beasley, R. Cardiovascular and hypokalaemic effects of inhaled salbutamol, fenoterol and isoprenaline. Thorax 1989, 44: 136-140.

7. Burgess, C.D., Turner, P. \& Wadsworth, J. Cardiovascular responses to mianserin hydrochloride: A comparison with tricyclic antidepressants. $B r J$ Clin Pharmacol 1978, 5 (suppl.1): $21-28$

8. Burgess, C.D., Wadsworth, J. \& Warrington, S.J. Evaluation of some non-invasive indices of cardiovascular function. $\mathrm{Br} J$ Clin Pharmacol 1979, 7: 436P.

9. Bazett, H.C. An analysis of the time relations of the electrocardiogram. Heart 1920, 7: 353-370.

10. Wallenstein, S., Zucker, C.L. \& Fleiss, J.L. Some statistical methods useful in circulation research. Circulation 1980, 47: $1-9$.

11. Strauss, M.H., Reeves, R.A., Smith, D.L., Leenen, F.H. The role of cardiac beta-1 receptors in the hemodynamic response to a beta-2 agonist. Clin Pharmac Ther 1986, 40: 108-115. tricular arrhythmias than either salbutamol or terbutaline. Indeed Tandon ${ }^{18}$ demonstrated that equal doses of fenoterol were associated with a greater frequency of ventricular ectopic beats than salbutamol and we have recently shown ${ }^{19}$ that the relative risk of asthma death is increased in asthmatics prescribed fenoterol either by metered dose inhaler or nebuliser when compared to other bronchodilator therapy, thus stressing the clinical relevance of this present study. Our results raise the possibility that in asthmatic patients with home nebulisers the disproportionate use of nebulised fenoterol among those who die may be due to the direct toxic effect of this agent, rather than different prescribing habits as previously postulated. ${ }^{2}$

\section{Acknowledgement}

We gratefully acknowledge Mrs Helen Bark for secretarial assistance.
12. Vincent, H.H., Boomsma, F., Man in 't Veld, A.J., Derkx, F.H.M., Wenting, G.J. \& Schalekamp, M.A.D.H. Effects of selective and non-selective beta agonists on plasma potassium and norepinephrine. J Cardiovasc Pharmacol 1984, 6: $107-114$.

13. Atwell, D. \& Lee, J.A. A cellular basis for the primary long Q-T syndromes. Lancet 1988, i: 1136-1138.

14. Greenberg, M.L., Lerman, B.B., Shipe, J.R., Kiaiser, D.L. \& DiMarco, J.P. Relation between amiodarone and desethylamiodarone plasma concentrations and electrophysiological effects, efficacy and toxicity. J Am Coll Cardiol 1987, 9: $1148-1155$

15. Burgess, C., Flatt, A., Siebers, R., Crane, J., Beasley, R. \& Purdie, G. A comparision of the extent and duration of hypokalaemia following three nebulised beta-2 agonists. Eur J Clin Pharmacol 1989, 36: 415-417.

16. Scheinin, M., Koulu, M., Laurikainen, E. \& Allonen, H. Hypokalaemia and other non-bronchial effects of inhaled fenoterol and salbutamol: a placebo-controlled dose response study in healthy volunteers. Br J Clin Pharmacol 1987, 24: 645-653.

17. Brittain, R.T., Dean, C.M. \& Jack, D. Sympathomimetic bronchodilator drugs. Pharmacol Ther Bull 1976, 2: 423-462.

18. Tandon, M.K., Cardiopulmonary effects of fenoterol and salbutamol aerosols. Chest 1980, 77: 429-431.

19. Crane, J., Pearce, N., Flatt, A. et al. Prescribed fenoterol and death from asthma in New Zealand, 1981-83: Case-control study. Lancet 1989 , i, 917-922. 